\title{
Discrimination of Two Phycoerythrin-Pigment Types of Synechococcus and Their Seasonal Succession in the Uwa Sea
}

\author{
TOSHIYA KATANO ${ }^{1}$, MiHO HIROSE ${ }^{2}$ and SHIN-ICHI NAKANO ${ }^{1,3 *}$ \\ ${ }^{1}$ Center for Marine Environmental Studies, Ehime University, 3 Bunkyo-cho, Matsuyama, Ehime 790-8577, \\ Japan \\ ${ }^{2}$ BD Bioscience, Nippon Becton Dickinson Company, Ltd, 2-2, Minatoshima Minamimachi 2-chome, Chuo-ku, \\ Kobe, Hyogo 650-0047, Japan \\ ${ }^{3}$ Present address: Faculty of Agriculture, Ehime University, 3-5-7 Tarumi, Matsuyama, Ehime 790-8566, Japan
}

(Received April 7, 2003-Accepted November 4, 2003)

We identified phycoerythrin-pigment phenotypes of Synechococcus strains in samples obtained from the Uwa Sea, and investigated the seasonal changes in the pigment-type composition of the Synechococcus community in this sea from January 2001 to March 2002. Two Synechococcus strains (UT01 and UT02) with different flow cytometric signatures were isolated by sorting and subsequent culturing. Excitation spectra showed that these two strains possessed different ratios of phycourobilin (PUB) to phycoerythrobilin (PEB). Flow cytometric signatures of the two types were also different; UT01 showed a higher green to red fluorescence ratio than UT02. The ranges of green to red fluorescence intensity of the strains did not overlap, though the strains were cultured under various light intensities (7-160 $\left.\mu \mathrm{E} \mathrm{m}^{-2} \mathrm{~s}^{-1}\right)$. In seawater samples, we could divide Synechococcus into lowerand higher-PUB types based on the ratio. There were two peaks of total Synechococcus abundance in June $\left(2.8 \times 10^{5}\right.$ cells ml $\left.{ }^{-1}\right)$ and August $\left(1.6 \times 10^{5}\right.$ cells ml $\left.^{-1}\right)$ in the upper layer at a depth of 0 to $15 \mathrm{~m}$. Major types during these two peaks were different; the higher-PUB type contributed $75.6 \%$ to the total Synechococcus community in June, and the lower-PUB type, 58.6\% in August. This is the first report which describes the seasonal succession of two phycoerythrin-pigment types of Synechococcus in a coastal sea.

Key words: Synechococcus, chromophore, seasonal succession, flow cytometry

Synechococcus distributed ubiquitously in oceans and coastal seas is one of the most important components of primary producers especially in oligotrophic marine environments ${ }^{12,17)}$. These bacteria possess phycobiliproteins (phycoerythrin, phycoerythrocyanin, phycocyanin and allophycocyanin) as light-harvesting pigments. The peak wavelength of absorbance for each phycobiliprotein depends on the composition of binding chromophores such as phycourobilin (PUB), phycoerythrobilin (PEB) and phycocyanobilin $(\mathrm{PCB})^{10)}$. Many phycoerythrin-rich Synechococcus strains have so far been isolated from various marine environments ${ }^{1,15,16)}$. They are divided into at

\footnotetext{
* Corresponding author; E-mail: shin@agr.ehime-u.ac.jp, Tel \& Fax: +81-89-927-8551
}

least three types using the ratio of PUB to PEB: a no-PUB type, low-PUB type and high-PUB type e $^{2,37}$.

PUB and PEB respectively have absorption maxima at ca. 495 and $545 \mathrm{~nm}^{10)}$. Glover et al. (1986) reported that Synechococcus strain WH7803, containing PUB, was able to use a low flux of blue light more efficiently for both photosynthesis and growth than could Synechococcus WH7805, which lacks PUB. The ratio of PUB to PEB in Synechococcus cells is an important phenotype which affects their photosynthesis and growth rates in coastal seas.

In previous studies, the high-PUB type dominated in the North Pacific Ocean ${ }^{2)}$ and the North Atlantic Ocean ${ }^{7)}$, while the low-PUB type dominated only in coastal waters of the Arabian $\mathrm{Sea}^{3}$, North Atlantic Ocean and Pacific Ocean ${ }^{8)}$ where the high-PUB type was also found. To understand the 
ecological role of Synechococcus communities in coastal seas, evaluations of pigment-type composition are important. However, information about the composition of Synechococcus populations in the Western Pacific Ocean is still limited. The succession of each phenotype in the Synechococcus community should be followed.

The aim of the present study is to clarify types of Synechococcus in the Uwa Sea that facing the West Pacific Ocean. First, we isolated two Synechococcus strains with different pigment types. Then, we separately determined cell densities of each type with a flow cytometer in the sea from January 2001 to March 2002.

\section{Materials and Methods}

The present study was carried out at a station (St. Ub) in the Uwa Sea located southwest of Ehime Prefecture, Japan (Fig. 1). The station is $500 \mathrm{~m}$ offshore where water depth is ca. $50 \mathrm{~m}$. The water samples were collected monthly from January 2001 to March 2002 with a 6 liter Van-Dorn water sampler. Samples were taken from water depths of 0, 2, 5, $10,15,20,30,40$ and $50 \mathrm{~m}$. Water temperature was measured vertically with a CTD profiler (Arec Electronics, Japan). The samples were stored in a 20 -liter polyethylene tank and brought to the labratory.

From the sample collected at $10 \mathrm{~m}$ on 19 December, cells of Synechococcus were sorted with a flow cytometer (FACSvantage SE, Becton Dickinson, USA) equipped with a water-cooled Argon laser (488 nm, 1 W, Coherent, USA) using the relative intensity of green and red fluorescence under blue-light excitation and incubated under a white fluorescent lamp $\left(20 \mu \mathrm{E} \mathrm{m}^{-2} \mathrm{~s}^{-1}\right)$ at $20^{\circ} \mathrm{C}$ in aged seawater enriched with $\mathrm{NaNO}_{3}$ and $\mathrm{Na}_{2} \mathrm{HPO}_{4}$ at final concentrations of $40 \mu \mathrm{mol} \mathrm{N}{ }^{-1}$ and $2 \mu \mathrm{mol} \mathrm{P} \mathrm{l^{-1 }}$, respectively. We isolated two Synechococcus strains by serial dilution. The strains were analyzed for their chromophore composition with a fluorescence spectrophotometer (F-2500, Hitachi, Japan) at $570 \mathrm{~nm}$ as a function of excitation wavelength.

The sea water samples were filtered through $2 \mu \mathrm{m}$ poresize polycarbonate filters to remove larger particles. The filtered seawater samples were used to make counts of each pigment type with a flow cytometer. Another portion of the water sample was filtered through a $0.1 \mu \mathrm{m}$ pore-size membrane filter (Millipore, USA), and the filtrate was used as sheath fluid. Forward scatter, side scatter, and three fluorescence intensities (red, 675-715 nm; orange, 564-586 nm; green, 515-545 nm) were recorded for each Synechococcus cell. All parameters were normalized with $2 \mu \mathrm{m}$ fluorescent beads (Polyscience Inc., USA). The beads were also used as an internal standard for the enumeration of Synechococcus cells ${ }^{9)}$.

Dual-beam flow cytometry has been used to discriminate between types of Synechocccus based on PUB and PEB fluorescence ${ }^{7,8)}$. In the present study, we used a single-beam flow cytometer to distinguish two types of Synechococcus in a seawater sample (Fig. 3). The rationale for the discrimination is described in following paragraphs.

First, Synechococcus cells with higher levels of PUB emit more orange light under blue excitation. Olson et al. (1988) pointed out that the orange fluorescence intensity excited by $488 \mathrm{~nm}$ reflects relative PUB content. They also stated that phycoerythtrin fluorescence intensity per cell increased with depth up to a factor of 30 , apparently as a result of photoadaptation. Thus, it is difficult to discriminate between two types based only on the fluorescence intensity of the cell.

Second, the ratio of green to orange fluorescence under blue light excitation should indicate the ratio of PUB to $\mathrm{PEB}^{2,3}$. Some of the energy of excited PUB is emitted as

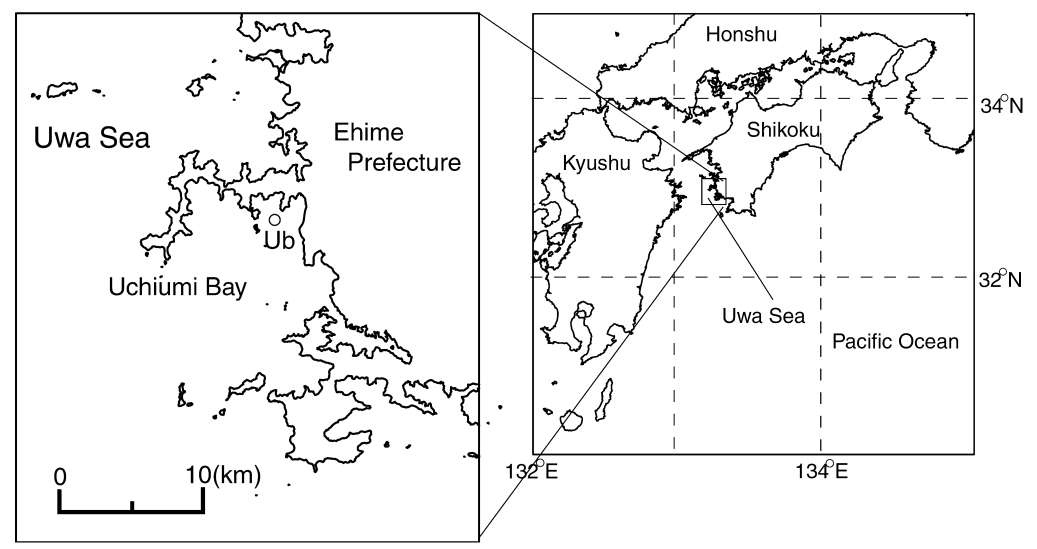

Fig. 1. Map of the Uwa Sea. 
green fluorescence, although most is transferred to PEB and $\mathrm{PCB}^{7,16}$. Toledo and Palenik (1997) showed that low- and high-PUB types could be easily identified in a mixed laboratory sample when grown under low light. However under high light, distinguishing between these types was difficult ${ }^{14}$. Thus, the difference in the ratio between the two was not great enough for the discrimination in seawater samples.

Third, the most powerful index for the discrimination of subpopulations in seawater samples was the ratio of green to red fluorescence. Types were easily distinguished based on the ratio of green to red fluorescence intensity under blue-light excitation. However, this index indicates the ratio of PUB to chl. $a$ fluorescence intensity.

For reasons mentioned above, we distinguished between phycoerythrin-pigment phenotypes by gating two subpopulations with green and red fluorescence, confirming that the subpopulations are similar in size with side and/or forward scatter, and finally confirming that the subpopulation with the higher green to red ratio corresponds to that with the higher green to orange ratio.

To evaluate the ranges of green and red fluorescence intensities of the two pigment types, we cultured the strains (UT01 and UT02) under various light intensities $(7,15,24$, 40,86 and $\left.160 \mu \mathrm{E} \mathrm{m}^{-2} \mathrm{~s}^{-1}\right)$. After 8 days of incubation, these cultures were analyzed with a flow cytometer. We also calculated the ratio of the two strains. The ratios of each type in all seawater samples were also calculated using the results obtained from the flow cytometric analysis.

We divided the water column into two layers: the upper layer at a depth of 0 to $15 \mathrm{~m}$ and the deeper layer at a depth of 20 to $50 \mathrm{~m}$. All the data shown in this paper are mean values of $0,2,5,10$ and $15 \mathrm{~m}$ depths for the upper layer and 20, 30, 40 and $50 \mathrm{~m}$ depths for the deeper layer.

\section{Results}

We cultured two strains of Synechococcus (UT01 and UT02) from the same water sample. Phycoerythrin-pigment type was examined using excitation spectra (Fig. 2). Peaks were obtained at $545 \mathrm{~nm}$ and $495 \mathrm{~nm}$ corresponding to PUB and PEB, respectively. Thus, both these strains possessed PUB and PEB chromophores. The peak height of PUB was lower than that of PEB in UT01, while the two were similar in UT02. The ratio of PUB to PEB in strain UT01 was similar to that in Synechococcus strain WH78037). The ratio was lower in UT02 than high-PUB types such as Synechococcus strains CC9317 and CC9318 where it ranged between 1.7 and 1.9, but similar between UT02 and Synechococcus

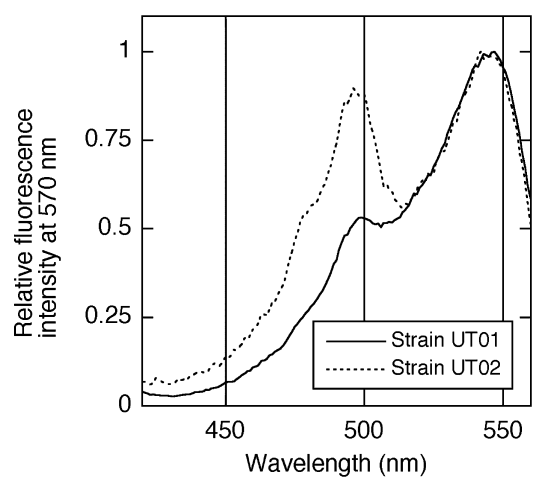

Fig. 2. Fluorescence emission of cultured Synechococcus at $570 \mathrm{~nm}$ as a function of excitation wavelength.
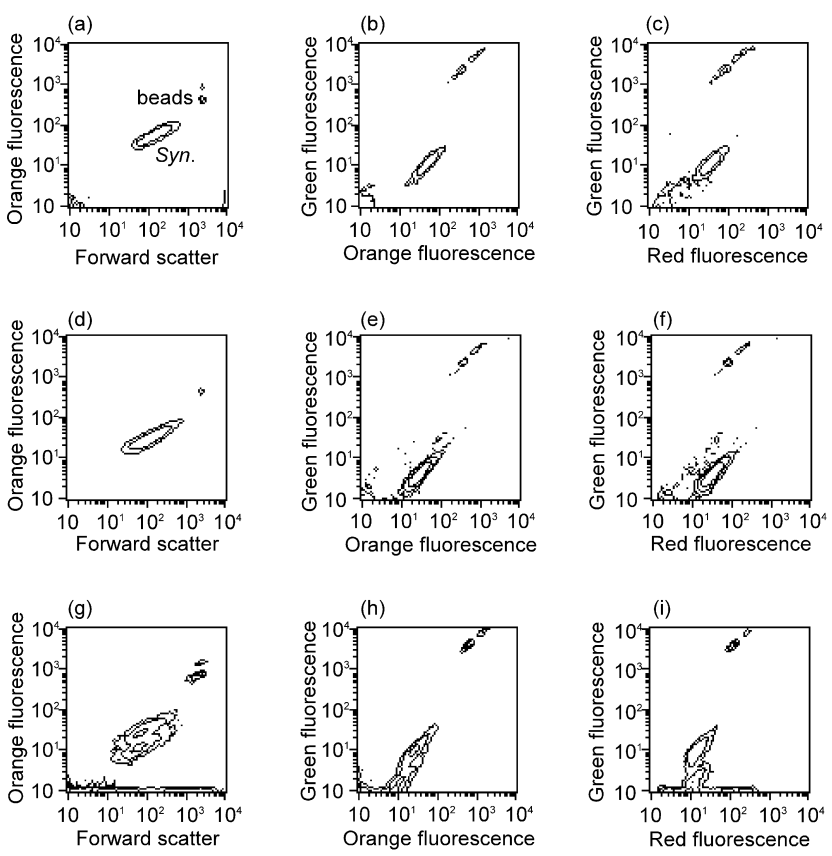

Fig. 3. Flow cytometric signatures of Synechococcus cells under blue light excitation $(488 \mathrm{~nm})$ : strain UT02 (a, b, c); strain UT01 (d, e, f); Synechococcus community collected at a depth of $20 \mathrm{~m}$ on 10 September 2001 (g, h, i). Vertical axes show orange fluorescence ( $(a, d, g)$ and green fluorescence $(b, c, e, f, h, i)$. Horizontal axes show forward scatter (a, d, g), red fluorescence (c, f, i), and orange fluorescence $(\mathrm{b}, \mathrm{e}, \mathrm{h})$. Fluorescence beads $(2 \mu \mathrm{m})$ were used as an internal standard.

strain WH8103 $(1.1)^{11)}$.

The flow-cytometric signatures of the two Synechococcus strains in the present study were different (Fig. 3b, c, e, and f) though cell sizes of the two strains were similar (Fig. 3a, d). The orange and red fluorescence intensities of UT01 and UT02 were roughly similar (Fig. 3b, c, e, and f). However, the green fluorescence of UT02 was obviously stronger than 

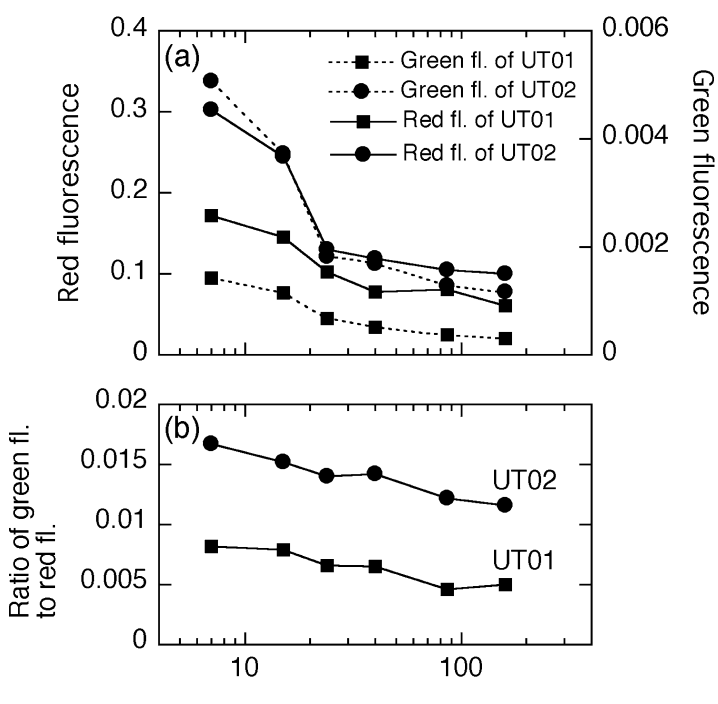

Light intensity $\left(\mu \mathrm{E} \mathrm{m} \mathrm{m}^{-2} \mathrm{~s}^{-1}\right)$

Fig. 4. Changes in the ratio of green to red fluorescence intensity analyzed with a flow cytometer (a), and green and red fluorescence intensities (b) of strains UT01 and UT02 incubated under different light intensities.

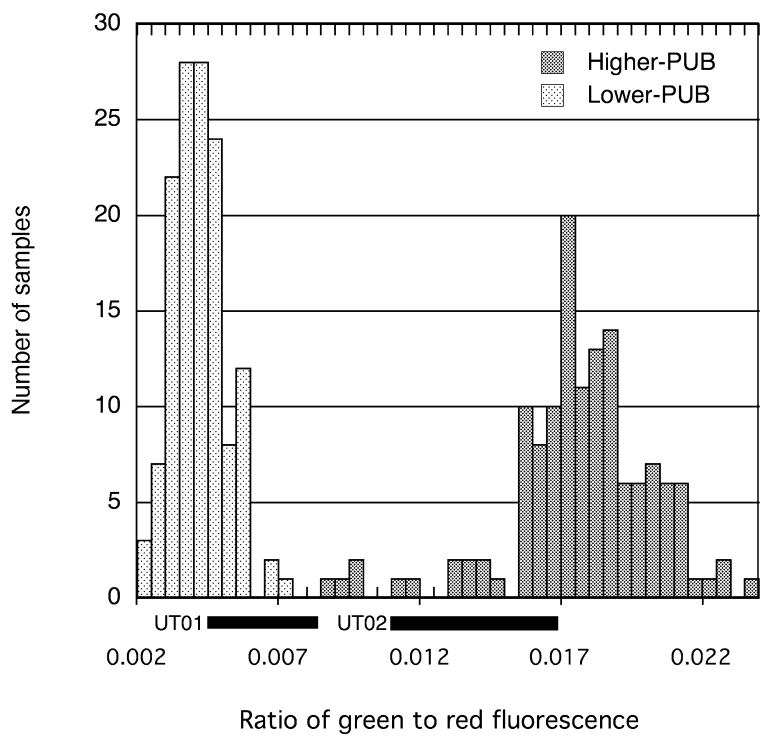

Fig. 5. Distribution of the ratio of green to red fluorescence intensity of the Synechococcus cells in natural samples analyzed with a flow cytometer. Bars under the panel show the ranges of the ratio of strains UT01 and UT02.

that of UT01. In a natural sample, we found two types of Synechococcus (Fig. 3h, i). The two types were more easily discriminated based on green and red fluorescence. Thus, the ratio of green to red fluorescence was considered to be a good indicator of phycoerythrin-pigment phenotypes.
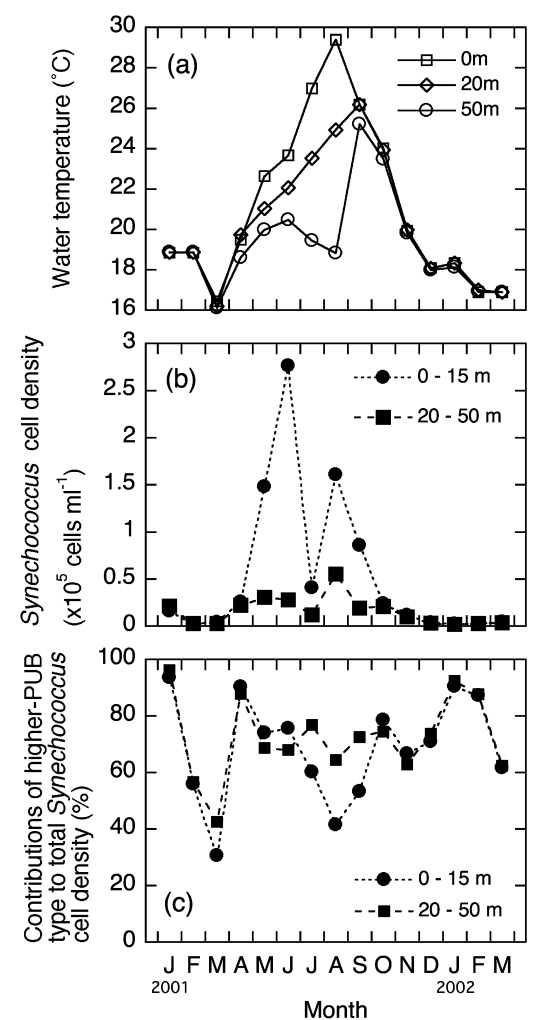

Fig. 6. Seasonal changes in water temperature (a), cell density of the Synechococcus community (b) and the contribution of the higherPUB type to the Synechococcus community (c).

The green and red fluorescence intensities increased in the cells cultured under low light ( 7 and $15 \mu \mathrm{E} \mathrm{m}^{-2} \mathrm{~s}^{-1}$, Fig. 4a). However, the ratio of green to red fluorescence intensity within each strain was relatively stable, and the range of values did not overlap (Fig. 4b, Fig. 5). The ratios of these two types in the seawater samples collected from depths with various relative-light intensities again did not overlap during the investigation period (Fig. 5). From these results, we conclude that the Synechococcus community in the Uwa Sea consists of two types: one with a higher PUB to PEB ratio (higher-PUB type), and the other with a lower PUB to PEB ratio (lower-PUB type). We followed seasonal changes in the cell density of each type.

Water temperature at the surface was lowest in February $\left(16^{\circ} \mathrm{C}\right)$ and highest in August $\left(29^{\circ} \mathrm{C}\right)$, and thermal stratification developed from April to September (Fig. 6a). Cell densities of Synechococcus in the upper layer of 0 to $15 \mathrm{~m}$ remained high $\left(>1 \times 10^{5}\right.$ cells ml $\left.{ }^{-1}\right)$ during the stratified period (Fig. 6b). There were two distinct peaks of abundance in June and August. The highest density was recorded in June $\left(2.8 \times 10^{5}\right.$ cells ml-1). Cell densities of Synechococcus in the 
deeper layer of 20 to $50 \mathrm{~m}$ were also relatively high during the stratified period, but the increases were not remarkable relative to those of the upper layer (Fig. 6b). Low cell densities of Synechococcus were detected during the destratified period, and no difference in cell density could be found between the upper and deeper layers (Fig. 6b).

The relative contribution of the higher-PUB type to total Synechococcus abundance from January to June remained high (75 to 95\%) except in February and March in the upper layer, and remarkably decreased from July to September with a minimum of $40 \%$ in August (Fig. 6c). It increased again from October onwards. The relative contribution in the deeper layer showed a similar seasonal pattern without the decrease from July to September. When Synechococcus abundance exceeded $10^{5}$ cells $\mathrm{ml}^{-1}$ in June (Fig. 6b), the higher-PUB type contributed $75 \%$ to the total Synechococcus community (Fig. 6c). In contrast, the higher-PUB type contributed only $40 \%$ when the cyanobacterial density exceeded $10^{5}$ cells ml ${ }^{-1}$ again in August (Fig. 6b, c). The highest cell density of the higher-PUB type was recorded in June $\left(2.09 \times 10^{5}\right.$ cells $\left.\mathrm{ml}^{-1}\right)$, while the cell density of the lowerPUB type was highest in August $\left(0.94 \times 10^{5}\right.$ cell ml-1).

\section{Discussion}

In coastal seas, the importance of picophytoplankton has been neglected because of the dominance of larger phytoplankton. The study of picophytoplankton in coastal waters of the Western Pacific Ocean has also been limited. In the Uwa Sea, the fraction of chl. $a$ less than $2 \mu \mathrm{m}$ in size contributes up to $80 \%$ of the total (Hirose, pers. comn.). Thus, an ecological study of Synechococcus is important for understanding the community structure of phytoplankton in the Uwa Sea.

We used the ratio of green to red fluorescence intensity to distinguish between the phycoerythrin-pigment phenotypes. The ratio that reflects relative intensities of PUB and chlorophyll fluorescence was relatively stable (Fig. 4). The ratio is a useful index for studying phycoerythrin-pigment phenotypes in marine environments, because most flow cytometers are equipped with a single laser $(488 \mathrm{~nm})$.

Both the lower- and higher-PUB types were detected throughout the study period (Fig. 6c). Olson et al. (1990) reported that the low-PUB type was detected at 40 out of 81 stations in coastal seas, and that 34 out of these 40 stations had both low- and high-PUB types. In the Arabian Sea, lowPUB types were more abundant at coastal stations ${ }^{3)}$. In the open ocean, only the high-PUB type has been found. The dominant Synechococcus in the North Atlantic and East
Pacific Oceans was the high-PUB type ${ }^{7,8)}$. Campbell and Vaulot (1993) showed that only the high-PUB type was detected at a station off Hawaii. Thus, the coexistence of two types of Synechococcus might be characteristic of coastal seas. Coastal seas are probably affected by river inflow, human activities and other factors all of which would have negligible effects on the open ocean. Thus, the environmental conditions in coastal seas would be variable, and this is a possible reason for the detection of the two types.

The present study first shows that the seasonal changes in the abundance of the two types differed. The highest cell density of the lower-PUB type was found in June, while that of the higher-PUB type occurred in August. As a result, the major type during the two peaks of Synechococcus cell densities in June and August was different (Fig. 6b, c). In June, more than half of all Synechococcus abundance was accounted for by the higher-PUB type, while the predominant pigment type in August was the lower-PUB type (Fig. 6b, c). The results suggest that the optimal temperature and/or other environmental factors for growth differ for each type of Synechococcus.

The light environment may be one of the most important factors affecting pigment-type composition in Synechococcus. There is plenty of light available in the upper layer, suggesting that underwater light quality is less important in determining the dominant type of Synechococcus. In August and September, the lower-PUB type dominated in the upper layer, while the higher-PUB type dominated in the deeper layer (Fig. 6b, c). Similar results were obtained by Olson et al. (1990), who found that vertical distributions of low-PUB types were restricted to shallower depths. These results suggest that a high light intensity favors the low-PUB type. The low-PUB strain WH7803 showed a high rate of growth even under a light intensity of $2000 \mu \mathrm{E} \mathrm{m}^{-2} \mathrm{~s}^{-15)}$, though it is known that phytoplankton at the surface often exhibit photoinhibition under high light intensities.

In the deeper layer, the quality of light may strongly affect the pigment-type composition of the Synechococcus community. The high-PUB type efficiently uses blue light because of its high content of PUB, while the low-PUB type uses green light ${ }^{6}$. The dominant light below $15 \mathrm{~m}$ in the open ocean is blue light with a wavelength of $440-490 \mathrm{~nm}^{6}$. Wood (1985) demonstrated a high rate of photosynthesis by PUB-containing Synechococcus strain in the deeper layer of the Pacific Ocean. Thus, the dominance of the high-PUB type in the deeper layer may be due to the dominance of blue light in the Uwa Sea though we did not examine the light environment in the sea.

Before May 2002 and after October 2002, water tempera- 
ture, total Synechococcus cell density and pigment-type composition of Synechococcus were almost the same between the upper and deeper layers (Fig. 6). For more than half the year, seawater might be vertically mixed at the station. Takeoka et al. (1997) reported that thermal stratification was much weaker in our sampling area than offshore probably due to stagnant tidal currents. For elucidation of the difference in the vertical distribution of each pigment type, the depth of the mixing layer and duration of stratification would be important. In situ incubation experiments and field observations should clarify the relationship between the light environment (light intensity and quality) and the pigment-type composition of Synechococcus in the sea.

\section{Acknowledgements}

We are grateful to T. Hirose, K. Hyodo and other staff members of the Uchiumi Institute of Oceanic and Fishery Science for their help in field sampling. Thanks are also due to Dr. K. Shimada for helpful discussions. The present study was partly supported by Grant-in-Aid for Scientific Research No. 12308027, JSPS, and the Research Fund of the coastal environment in Uchiumi Bay, Uchiumi Village, Ehime Prefecture.

\section{References}

1) Brahamsha, B. 1996. A genetic manipulation system for oceanic cyanobacteria of the genus Synechococcus. Appl. Environ. Microbiol. 62: 1747-1751.

2) Campbell, L. and D. Vaulot. 1993. Phoyosynthetic picoplankton community structure in the subtropical North Pacific Ocean near Hawaii (station ALOHA). Deep-Sea Res. I 40: 2043-2060.

3) Campbell, L., M.R. Landry, J. Constantinou, H.A. Nolla, S.L. Brown, H. Liu and D.A. Caron. 1998. Response of microbial community structure to environmental forcing in the Arabian Sea. Deep-Sea Res. II 45: 2301-2325.

4) Glover, H.E., M.D. Keller and R.R.L. Guillard. 1986. Light Quality and oceanic ultraphytoplankters. Nature 319: 142-143.

5) Kana, T.M. and T.M. Glibert. 1986. Effects of irradiences up to $2000 \mu \mathrm{E} \mathrm{m}^{-2} \mathrm{~s}^{-1}$ on marine Synechococcus WH7803-I. Growth, pigmentation, and cell composition. Deep-Sea Res. I 34: 479495.
6) Kirk, J.T.O. 1994. Light \& photosynthesis in aquatic ecosystems. Cambridge University Press, Cambridge.

7) Olson, R.J., S.W. Chisholm, E.R. Zettler and E.V. Armbrust. 1988. Analysis of Synechococcus pigment types in the sea using single and dual beam flow cytometry. Deep-Sea Res. 35: 425440.

8) Olson, R.J., S.W. Chisholm, E.R. Zettler and E.V. Armbrust. 1990. Pigments, size, and distribution of Synechococcus in the North Atlantic and Pacific Oceans. Limnol. Oceanogr. 35: 45-58.

9) Olson, R.J., E.R. Zettler and M.D. DuRand. 1993. Phytoplankton analysis using flow cytometry, p. 175-186. In P.F. Kemp, B.F. Sherr and J.J. Cole (ed.), Handbook of methods in aquatic microbial ecology. Lewis Pubishers, Baca Raton.

10) Ong, L.J., A.N. Glazer and J.B. Waterbury. 1984. An unusual phycoerythrin from a marine cyanobacterium. Science 224: 80 83.

11) Palenik, B. 2001. Chromatic adaptation in Marine Synechococcus strains. Appl. Environ. Microbiol. 67: 991-994.

12) Stockner, J.G. and N.J. Antia. 1986. Algal picoplankton from marine and freshwater ecosystems: a multidisciplinary perspective. Can. J. Fish. Aquat. Sci. 43: 2472-2503.

13) Takeoka, H., A. Kaneda and H. Anami. 1997. Tidal fronts induced by horizontal contrast of vertical mixing efficiency $\mathrm{J}$. Oceanogr. 53: 563-570.

14) Toledo, G. and B. Palenik. 1997. Synechococcus diversity in the California Current as seen by RNA polymerase ( $r p o C 1)$ gene sequences of isolated strains Appl. Environ. Microbiol. 63: 4298-4303.

15) Toledo, G., B. Palenik and B. Brahamsha. 1999. Swimming marine Synechococcus strains with widely different photosynthetic pigment ratios form a monophyletic group. Appl. Environ. Microbiol. 65: 5247-5251.

16) Waterbury, J.B., S.W. Watson, F.W. Valois and D.G. Franks. 1986. Biological and ecological characterization of the marine unicellular cyanobacterium Synechococcus. In: Photosynthetic picoplankton (Platt, T., Li, W.K.W., Eds.) Can Bull. Fish Aquat. Sci. 214: 71-120.

17) Weisse, T. 1993. Dynamics of autotrphic picoplankton in marine and freshwater ecosystems, p. 327-370. In J.G. Jones (ed.), Advances in Microbes and Ecology, vol. 13, Plenum Press, New York.

18) Wood, A.M. 1985. Adaptation of photosynthetic apparatus of marine ultraphytoplankton to natural light fields. Nature 316: 253-255.

19) Wood, A.M., P.K. Horan, K. Muirhead, D.A. Phinney, C.M. Yentsch and J.B. Waterbury. 1985. Discrimination between types of pigments in marine Synechococcus spp. by scanning spectroscopyy, epifluorescence microscopy, and flow cytometry. Limnol. Oceanogr. 30: 1303-1315. 